\title{
Preparedness to Combat Determinants of Underweight-Based Child Malnutrition in Flood-Affected Areas of Pakistan
}

\author{
Ijaz ul Haq $\mathbb{D}^{1}$, Xiang He $\mathbb{D}^{2},{ }^{2}$ Abdul Majid Mujahid $\mathbb{D},^{3}$ Hira Ibrahim $\left(\mathbb{D},{ }^{4}\right.$ \\ Zafar Mehmood $₫{ }^{5}$ Jahan Shah $\left({ }^{6}{ }^{6}\right.$ Bilal Ahmed $\left(1,{ }^{7}\right.$ Amjad Khan $\left({ }^{1},{ }^{1}\right.$ \\ Shahbaz Ahmad Zakki $\oplus^{1},{ }^{1}$ Ihtisham Ul Haq ${ }^{1},{ }^{1}$ Muhammad Shahzad $\left(1,{ }^{1}\right.$

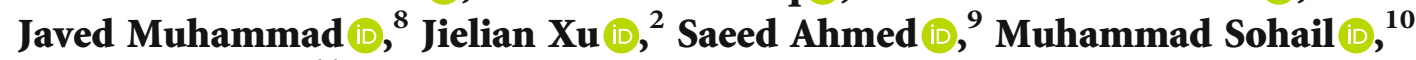 \\ and Jing Miao ${ }^{11}$ \\ ${ }^{1}$ Department of Public Health \& Nutrition, The University of Haripur, Haripur, Khyber Pakhtunkhwa, Pakistan \\ ${ }^{2}$ Department of Clinical Nutrition, The Affliated Jiangning Hospital of Nanjing Medical University, Nanjing, Jiangsu 211100, China \\ ${ }^{3}$ Basic Health Unit Daiwal, Tehsil/District Khushab, District Health Authority Khushab, Punjab, Pakistan \\ ${ }^{4}$ Jinnah Burn and Reconstructive Surgery Center Lahore, Pakistan \\ ${ }^{5}$ Department of Math's, Stats \& Computer Science, The University of Agriculture Peshawar, Pakistan \\ ${ }^{6}$ Department of Social Medicine and Health Education, School of Public Health, Nanjing Medical University, \\ Jiangsu Province, China \\ ${ }^{7}$ School of Pharmacy, Nanjing Medical University, Nanjing, Jiangsu 211166, China \\ ${ }^{8}$ Department of Microbiology, The University of Haripur, Haripur, Khyber Pakhtunkhwa, Pakistan \\ ${ }^{9}$ Department of Biological Sciences, National University of Medical Sciences, Rawalpindi, Pakistan \\ ${ }^{10}$ School of Pharmacy, Key Laboratory of Molecular Pharmacology and Drug Evaluation, Yantai University, China \\ ${ }^{11}$ Department of Clinical Nutrition, Nanjing Tongren Hospital, School of Medicine, Southeast University, Nanjing, \\ Jiangsu 211100, China
}

Correspondence should be addressed to Xiang He; 781651165@qq.com and Jing Miao; miaoj@njtrh.org

Ijaz ul Haq and Xiang He contributed equally to this work.

Received 2 September 2021; Revised 1 December 2021; Accepted 20 December 2021; Published 25 January 2022

Academic Editor: Haruki Komatsu

Copyright ( $92022 \mathrm{Ijaz}$ ul Haq et al. This is an open access article distributed under the Creative Commons Attribution License, which permits unrestricted use, distribution, and reproduction in any medium, provided the original work is properly cited.

Aims. Floods badly impact the food and nutrition security in developing countries. The role of the government and the impact of floods on the underweight status of children in the affected areas is not clear. We aimed to find the determinants of underweight in flood-affected areas of Khyber Pakhtunkhwa, Pakistan. Methods. We used a multistage sampling technique and selected 656 households during in the flood-affected areas of Pakistan. Data were collected in the three most affected districts. A validated questionnaire was used to find socioeconomic and demographic information, hygiene, and sanitation information. We used logistic regression to find the determinants of underweight, controlling for confounders. Results. The prevalence of global malnutrition based on underweight was $25.2 \%$. The prevalence of underweight was higher in young age mothers (40.6\%), younger age children $(71.4 \%)$, large family size $(28.4 \%)$, joint family $(27 \%)$, and no toilet facility $(28.9 \%)$. District Nowshera was at high risk of underweight based undernutrition, followed by district Charsadda compared to children belonging to Dera Ismail Khan. The significant risk factor that causes underweight was child lower age $(p<0.01)$, young age of mothers $(p<0.01)$, children access to unimproved water sources $(p<0.01)$, and location (districts) due to environmental and constant flood consequences $(p<0.01)$. Conclusion. In conclusion, risk factors of underweight should be appropriately targeted in the flood-hit areas of Pakistan. Governments should preallocate budgetary resources and enhance the emergency preparedness levels to facilitate the communities with flooding incidents and their aftermath in the shape of child underweight-based malnutrition. 


\section{Introduction}

The nutritional status of children affected by flooding situations is studied in many parts of the world [1]. Malnutrition is a leading cause of morbidity and mortality in children and is widespread in developing countries [2], especially floodaffected areas [3]. Stunting is more common in disasterprone areas across the world. Underweight and stunting are very common in flooded communities compared with nonflooded areas in the same country with similar lifestyles [4]. Floods have both, directly and indirectly, impact on the underweight status. The direct impact of floods is a shortage of food required for proper nutrition and disruption of essential food items supply [5]. Contrarily, the flood also results in loss of income, homelessness, food cooking, production, contamination, displacing the children, contamination of water, and food sources $[6,7]$.

Literature reveals strong linkages of flooding and the underweight situation of children in South Asian countries, including India and Pakistan [8]. Developing countries face challenges of the underweight and stunting situation resulting in flood situations. Cascading events in floods often bring diseases like typhoid, diarrhea, dengue, malaria that collectively contribute to underweight, stunting, and wasting conditions for the children in certain communities. Management of such events most often requires multisectoral coordination and collaborations by many of the government agencies. There are four important response features to the floods by the governments containing, (a) safety and security of the people and their property, (b) supply of food and water items, (c) public health safety and security to protect the health of all, especially children, and (d) attain normal social life [9-11].

The demographic settlements of communities in highrisk vulnerable areas are affected many times by flooding. Most of such societies belong to countries India, Pakistan, Nepal, and Bangladesh. Children who belong to those vulnerable communities are often found underweight and stunted [12]. The flood in 2010 in Pakistan was a major disaster that affected nearly 21 million people and 11000 villages. It impacted the health status of the people in many ways [13]. The flood brought many short-term and longterm consequences for the government of Pakistan. In this disaster, the government has to manage child health and underweight issues by considering the loss of safe food, eliminating standing crops, transportation of dietary items to affected areas, decontamination of water reservoirs, loss of livestock resulting in meat and milk scarcity, and essential medications.

Underweight is one of the essential anthropometric measures of observing child malnutrition and is a combined form of undernutrition that comprises both stunting and wasting. It is defined as the percentage of preschool and school-going children whose weight for age is below minus two standard deviations (moderate and severe underweight) and minus three standard deviations (severe underweight) from the median of the WHO Child Growth Standards [14]. Underweight is related to deprived physical stamina to work and a weak immune system to resist diseases. More- over, the high prevalence of underweight monitors the continued existence of undernutrition during the crucial days of child growth.

UNICEF (2013) reported that in 2011, about 101 million children under five years of age, or approximately 16 percent of children, were underweight. The prevalence is highest in South Asia with 59 million underweight children, followed by sub-Saharan Africa has 30 million. Globally, the prevalence of underweight has been declined, from 25 percent in 1990 to 16 percent in 2011-a 37 percent reduction [15].

Since undernutrition, including underweight continues during child growth, it is necessary to investigate the disparity effect of underweight prevalence on diverse socioeconomic and demographic determinants. Also, it is necessary to state how the government should prepare and cope with the disaster situation and the aftermath of disasters in Pakistan. The current study aimed to find the determinants of underweight in preschool-going children (5-60 months) and school-going children ( $>5$ to 12 years of age) in the flood-affected areas of Khyber Pakhtunkhwa, Pakistan. We used underweight as a vital index of the nutritional status of children.

\section{Methods}

The cross-sectional study design was employed for this study in flood-affected areas of Khyber Pakhtunkhwa, Pakistan. Data was collected in 656 preschools and school-going children (1-12 years) in three affected districts, Charsadda, Nowshehra, and Dera Ismail Khan, from June 2014 to June 2016. The standard formula $\left(n=(1.96)^{2} \times 0.309(1-0.309)\right.$ $\left./(0.05)^{2}=328\right)$ was used for sample size calculation. The final calculated sample size was $n=656$, as estimated samples size " 328 " was multiplied with the assumed "2" design effect (DE).

Multistage and simple random sampling techniques were used to select tehsils and union councils (UCS) and subdivided according to villages in the selected districts. The trained personnel visited respondent's household at a specific interval. Children with chronic illnesses and those of nonconsenting parents were excluded from the research.

The University of Agriculture, Peshawar, Pakistan, ethical committee approved this research in accordance with the Declaration of Helsinki's guidelines (IRB\#002). Written informed consent was obtained from the research respondents.

A rapid assessment field survey questionnaire was developed in English and local languages (Urdu and Pashto) and pretested on 40 samples. Questionnaires were modified according to the initial data. Data were collected by trained and experienced personnel.

Demographic and socioeconomic informations were collected, which included gender, child and maternal age, household status (internally displaced persons (IDPs) or host), family size (small $=5$ members, medium $=5-10$ members, large $=>10$ members), family type (joint or nuclear family), father and mother's occupation (full-time working, part-time working, not working), monthly income 
TABle 1: Percentage distribution of underweight based malnutrition in preschool and school going children and its association with socioeconomic determinants.

\begin{tabular}{|c|c|c|c|c|c|c|}
\hline \multirow{4}{*}{$\begin{array}{l}\text { Factors } \\
\text { Gender }\end{array}$} & \multicolumn{6}{|c|}{ Malnutrition based on underweight } \\
\hline & & \multicolumn{2}{|c|}{$\begin{array}{l}\text { Normal } \\
>-2 S D\end{array}$} & \multicolumn{2}{|c|}{$\begin{array}{c}\text { Underweight } \\
<-2 S D\end{array}$} & \multirow{3}{*}{$\begin{array}{c}\text { Chi-square ( } p \text { value) } \\
1.23(0.266)\end{array}$} \\
\hline & Male & 290 & $78.2 \%$ & 81 & $21.8 \%$ & \\
\hline & Female & 213 & $74.7 \%$ & 72 & $25.3 \%$ & \\
\hline \multirow{4}{*}{ Age of child } & $1-12$ & 2 & $28.6 \%$ & 5 & $71.4 \%$ & \multirow{4}{*}{$85.5(<0.01)$} \\
\hline & $13-24$ & 19 & $42.2 \%$ & 26 & $57.8 \%$ & \\
\hline & $25-36$ & 29 & $46.8 \%$ & 33 & $53.2 \%$ & \\
\hline & $>36$ & 454 & $83.8 \%$ & 88 & $16.2 \%$ & \\
\hline \multirow{3}{*}{ Maternal age } & $15-24$ & 98 & $59.4 \%$ & 67 & $40.6 \%$ & \multirow{3}{*}{$38.95(<0.01)$} \\
\hline & $25-34$ & 208 & $80.6 \%$ & 50 & $19.4 \%$ & \\
\hline & $>34$ & 198 & $85.0 \%$ & 35 & $15.0 \%$ & \\
\hline \multirow{2}{*}{ Status of the household } & Host & 453 & $75.5 \%$ & 147 & $24.5 \%$ & \multirow{2}{*}{$6.97(0.008)$} \\
\hline & IDP & 51 & $91.1 \%$ & 5 & $8.9 \%$ & \\
\hline \multirow{2}{*}{ Family type } & Joint family & 206 & $73.0 \%$ & 76 & $27.0 \%$ & \multirow{2}{*}{$3.96(0.046)$} \\
\hline & Individual family & 298 & $79.7 \%$ & 76 & $20.3 \%$ & \\
\hline \multirow{3}{*}{ Family size } & Small & 134 & $80.7 \%$ & 32 & $19.3 \%$ & \multirow{3}{*}{$5.08(0.07)$} \\
\hline & Medium & 218 & $78.4 \%$ & 60 & $21.6 \%$ & \\
\hline & Large & 151 & $71.6 \%$ & 60 & $28.4 \%$ & \\
\hline \multirow{3}{*}{ Father occupation } & Not working & 26 & $76.5 \%$ & 8 & $23.5 \%$ & \multirow{3}{*}{$0.225(0.894)$} \\
\hline & Part time working & 25 & $73.5 \%$ & 9 & $26.5 \%$ & \\
\hline & Full time working & 453 & $77.0 \%$ & 135 & $23.0 \%$ & \\
\hline \multirow{3}{*}{ Mother occupation } & House wife & 480 & $77.2 \%$ & 142 & $22.8 \%$ & \multirow{3}{*}{$0.794(0.672)$} \\
\hline & Part time working & 10 & $71.4 \%$ & 4 & $28.6 \%$ & \\
\hline & Full time working & 14 & $70.0 \%$ & 6 & $30.0 \%$ & \\
\hline \multirow{3}{*}{ Income } & $5000-10000$ & 132 & $72.9 \%$ & 49 & $27.1 \%$ & \multirow{3}{*}{$3.67(0.16)$} \\
\hline & $10001-15000$ & 144 & $75.4 \%$ & 47 & $24.6 \%$ & \\
\hline & $>15000$ & 228 & $80.3 \%$ & 56 & $19.7 \%$ & \\
\hline \multirow{2}{*}{ Father education } & Literate & 270 & $78.3 \%$ & 75 & $21.7 \%$ & \multirow{2}{*}{$0.838(0.36)$} \\
\hline & Illiterate & 234 & $75.2 \%$ & 77 & $24.8 \%$ & \\
\hline \multirow{2}{*}{ Mother education } & Literate & 231 & $81.3 \%$ & 53 & $18.7 \%$ & \multirow{2}{*}{$5.71(0.017)$} \\
\hline & Illiterate & 273 & $73.4 \%$ & 99 & $26.6 \%$ & \\
\hline \multirow{2}{*}{ Water quality } & Improved & 423 & $78.9 \%$ & 113 & $21.1 \%$ & \multirow{2}{*}{$7.19(0.007)$} \\
\hline & Not improved & 81 & $67.5 \%$ & 39 & $32.5 \%$ & \\
\hline & Charsadda & 235 & $83.9 \%$ & 45 & $16.1 \%$ & \\
\hline District & Nowshera & 172 & $62.3 \%$ & 104 & $37.7 \%$ & $63.5(<0.01)$ \\
\hline & DIK & 97 & $97.0 \%$ & 3 & $3.0 \%$ & \\
\hline Toilet focility & Flush/pit latrine & 361 & $79.3 \%$ & 94 & $20.7 \%$ & $526(0020)$ \\
\hline 10met iacnimy & No facility & 143 & $71.1 \%$ & 58 & $28.9 \%$ & $0.20(0.022)$ \\
\hline
\end{tabular}

(Pakistani rupees), father and mother's education, quality of water (Improved sources and unimproved sources), and toilet facility (pit latrine, flush, no facility) at household.

Weight-for-age $Z$-score was used to evaluate underweight-based malnutrition for under-five children according to the WHO criterion [16-18]. For more than five years of children, NCHS references were used to find underweight status [19].

SPSS version 20.0 (SPSS, Chicago, IL, USA) was used for statistical analysis. Emergency Nutrition Assessment (http:// www.scribd.com) software was used for the calculation of $z$ -scores. We calculated odds ratio (OR) and 95\% confidence intervals (CIs) for the strength of association with underweight. Binary and ordinal logistic regression was used to find the determinants of underweight in the flood-affected region. A two-tailed $p<0.05$ was considered significant.

\section{Results}

Table 1 depicts the percentage distribution of underweightbased malnutrition in preschool and school-going children of the target population and its association with 
TABLE 2: Prevalence of malnutrition in children of age 5-60 months based on underweight by gender.

\begin{tabular}{|c|c|c|c|}
\hline & $\begin{array}{c}\text { All } \\
n=298\end{array}$ & $\begin{array}{c}\text { Boys } \\
n=158\end{array}$ & $\begin{array}{c}\text { Girls } \\
n=140\end{array}$ \\
\hline Prevalence of global malnutrition $(<-2 z$-score $)$ & $\begin{array}{c}\text { (75) } 25.2 \% \\
(20.6-30.495 \% \mathrm{CI})\end{array}$ & $\begin{array}{c}\text { (38) } 24.1 \% \\
(18.1-31.395 \% \mathrm{CI})\end{array}$ & $\begin{array}{c}\text { (37) } 26.4 \% \\
(19.8-34.395 \% \mathrm{CI})\end{array}$ \\
\hline Prevalence of moderate malnutrition $(<-2 z$-score and $\geq-3 z$-score $)$ & $\begin{array}{c}(36) 12.1 \% \\
(8.9-16.395 \% \mathrm{CI})\end{array}$ & $\begin{array}{c}\text { (21) } 13.3 \% \\
(8.9-19.595 \% \mathrm{CI})\end{array}$ & $\begin{array}{c}\text { (15) } 10.7 \% \\
(6.6-16.995 \% \mathrm{CI})\end{array}$ \\
\hline Prevalence of severe malnutrition ( $<-3 z$-score) & $\begin{array}{c}(39) 13.1 \% \\
(9.7-17.495 \% \mathrm{CI})\end{array}$ & $\begin{array}{c}\text { (17) } 10.8 \% \\
(6.8-16.695 \% \mathrm{CI})\end{array}$ & $\begin{array}{c}(22) 15.7 \% \\
(10.6-22.695 \% \mathrm{CI})\end{array}$ \\
\hline
\end{tabular}

TABle 3: Prevalence of acute malnutrition based on weight-for-age (underweight) $z$-score and by gender.

\begin{tabular}{|c|c|c|c|}
\hline & $\begin{array}{c}\text { All } \\
n=656\end{array}$ & $\begin{array}{c}\text { Boys } \\
n=371\end{array}$ & $\begin{array}{c}\text { Girls } \\
n=285\end{array}$ \\
\hline Prevalence of global malnutrition $(<-2 z$-score $)$ & $\begin{array}{c}(153) 23.3 \% \\
(20.2-26.7,95 \% \text { C.I })\end{array}$ & $\begin{array}{c}(81) 21.8 \% \\
(17.5-26.3,95 \% \text { C.I. })\end{array}$ & $\begin{array}{c}\text { (72) } 25.3 \% \\
(20.6-30.6,95 \% \text { C.I. })\end{array}$ \\
\hline Prevalence of moderate malnutrition $(<-2 z$-score and $\geq-3 z$-score $)$ & $\begin{array}{c}(108) 16.5 \% \\
(13.8-19.5,95 \% \text { C.I. })\end{array}$ & $\begin{array}{c}(60) 16.2 \% \\
(12.8-20.3,95 \% \text { C.I. })\end{array}$ & $\begin{array}{c}(48) 16.8 \% \\
(12.9-21.6,95 \% \text { C.I. })\end{array}$ \\
\hline Prevalence of severe malnutrition $(<-3 z$-score $)$ & $\begin{array}{c}(45) 6.9 \% \\
(5.2-9.1,95 \% \text { C.I. })\end{array}$ & $\begin{array}{c}(21) 5.7 \% \\
(3.7-8.7,95 \% \text { C.I. })\end{array}$ & $\begin{array}{c}\text { (24) } 8.4 \% \\
\text { (5.7-12.2, 95\%C.I.) }\end{array}$ \\
\hline
\end{tabular}

socioeconomic determinants. Prevalence of underweight decreased with child age (i.e., from $71.4 \%$ to $16.2 \%$ ). The proportion of underweight is high among mothers aged 15-24 and 25-36 years (40.6\% and 19.4\%, respectively). The majority $(24.5 \%)$ of hosted children are underweight. Children living in joint families $(27.0 \%)$ are more likely to be underweight than a child living in individual families (20.3\%). Regarding parental education, the prevalence of underweight is higher in children having illiterate fathers and mothers $(24.8 \%$ and $26.6 \%$, respectively). Underweight decreased with increasing income level (i.e., from $27.1 \%$ to $19.7 \%)$. More (32.5\%) children are malnourished concerning water quality and do not have improved water access. A majority (29.3\%) child are underweight, having no toilet facility in their households. The proportion of underweight is high $(37.7 \%)$ in district Nowshehra compared to the others two districts Charsadda and Dera Ismail Khan. The factors child age, maternal age, household status, family type, mother education, water quality, toilet facility, and districts are significantly $(p$ value $<0.05)$ associated with child underweight.

High underweight prevalence exists in preschool going children in the flood-hit areas of Khyber Pakhtunkhwa (Table 2), where approximately one in 4 children $(25.2 \%$; 20.6-30.4; 95\% CI) have a global prevalence of underweight based malnutrition (<-2 $z$-score) in children of age 5-60 months. Whereas approximately one in 8 children $(13.1 \%$; 9.7-17.4; 95\% CI) have a severe prevalence of underweightbased malnutrition (<-3 $z$-score) in children of age 5-60 months in flood-hit areas. It was also observed that the global prevalence of underweight in under five years of female children $26.4 \%(19.8-34.3 ; 95 \% \mathrm{CI})$ is greater than male children $24.1 \%$ (18.1-31.3; 95\% CI). Similarly, prevalence of underweight based severe malnutrition in female children $15.7 \%(10.6-22.6 ; 95 \% \mathrm{CI})$, respectively, is high as compared to male children $13.1 \%$ (9.7-17.4; 95\% CI) while prevalence of moderate malnutrition $(<-2 \quad z$-score and $\geq-3$ $z$-score) was found low in female children $10.7 \%$ (6.6-16.9; $95 \% \mathrm{CI})$ as compared to male children $13.3 \%$ (8.9-19.5; 95\% CI).

As shown in Table 3, among 656 children, the overall prevalence of underweight in the study sample is 153 $(23.3 \%)$ and is higher $72(25.3 \%)$ in girls than in boys 81 $(21.8 \%)$. The study also revealed that 108 (16.5\%) are moderately underweight, and $45(6.9 \%)$ are severely underweight. Similarly, 60 (16.2\%) boys and 48 (16.8\%) girls are moderately underweight. At last, 21 (5.7\%) boys and 24 $(8.4 \%)$ girls are severely underweight.

Figure S1 (a) shows the parentage of underweight and normal children in each age group and tells that there is a decreasing trend of malnutrition with the age of children because there is a high prevalence of stunting at low age groups as compared to higher age group (>36 months). Figure S1 (b) expresses the percentage of underweight and normal children for each age group calculated within the target population's overall percentage of underweight and normal children.

Figure S2 shows that out of the total sample of size 656, $57.74 \%$ of boys are with normal weights, whereas $42.26 \%$ of girls are with normal weights. It is evident from the figure that male children are slightly more susceptible to underweight-based malnutrition than female children in the flood-affected areas of Khyber Pakhtunkhwa.

Figure S3 shows that out of the total observed underweight children in the study area district, Nowshera is contributing the highest prevalence of underweight based malnutrition (68.42\%) followed by district Charsadda (46.63\%) and Dera Ismail Khan is the lowest (1.974\% only).

Figure S4 shows the pyramid for children age-stratified according to the districts. It has been shown that children belonging to district Nowshera were at high risk of underweight based undernutrition followed by district 
TABLE 4: Bivariate logistic regression table for underweight among preschool and school-going children in the flood-affected area of Khyber Pakhtunkhwa.

\begin{tabular}{|c|c|c|c|c|c|c|}
\hline \multirow[t]{2}{*}{ Factors } & \multirow[t]{2}{*}{ Odds ratio } & \multirow[t]{2}{*}{ Std. err. } & \multirow[t]{2}{*}{$z$} & \multirow[t]{2}{*}{$p>z$} & \multicolumn{2}{|c|}{ [95\% Conf. Interval] } \\
\hline & & & & & Lower & Upper \\
\hline \multicolumn{7}{|l|}{ Sex of the child } \\
\hline Male (r) & 1 & - & - & - & - & - \\
\hline Female & 0.9216108 & 0.2090305 & -0.36 & 0.719 & 0.59 & 1.44 \\
\hline \multicolumn{7}{|l|}{ Child age } \\
\hline $1-12$ & 6.916153 & 6.455428 & 2.07 & 0.038 & 1.11 & 13.09 \\
\hline $12-24$ & 5.839998 & 2.149672 & 4.79 & $<0.01$ & 3.84 & 12.02 \\
\hline $24-36$ & 4.780962 & 2.171283 & 5.98 & $<0.01$ & 2.62 & 12.70 \\
\hline$>36(\mathrm{r})$ & 1 & - & - & - & - & - \\
\hline \multicolumn{7}{|l|}{ Maternal age } \\
\hline $15-24$ & 2.893225 & 0.8597395 & 3.58 & $<0.01$ & 1.62 & 5.18 \\
\hline $25-34$ & 1.380087 & 0.3823612 & 1.16 & 0.245 & 0.80 & 2.38 \\
\hline$>34(\mathrm{r})$ & 1 & - & - & - & - & - \\
\hline \multicolumn{7}{|l|}{ Status of the $\mathrm{HH}$} \\
\hline $\operatorname{IDP}(r)$ & 1 & - & - & - & - & - \\
\hline Host & 1.803671 & 0.981647 & 1.08 & 0.278 & 0.62 & 5.24 \\
\hline \multicolumn{7}{|l|}{ Family type } \\
\hline Individual family (r) & 1 & - & - & - & - & - \\
\hline Joint family & 1.244094 & 0.3063098 & 0.89 & 0.375 & 0.77 & 2.02 \\
\hline \multicolumn{7}{|l|}{ Family size } \\
\hline Small (r) & 1 & - & - & - & - & - \\
\hline Medium & 1.365517 & 0.4075388 & 1.04 & 0.297 & 0.76 & 2.450972 \\
\hline Large & 1.089051 & 0.3660427 & 0.25 & 0.800 & 0.56 & 2.10 \\
\hline \multicolumn{7}{|l|}{ Father occupation } \\
\hline Not working & 0.8523584 & 0.4186163 & -0.33 & 0.745 & 0.32 & 2.23 \\
\hline Part time working & 1.255285 & 0.6529761 & 0.44 & 0.662 & 0.45 & 3.48 \\
\hline Full time working (r) & 1 & - & - & - & - & - \\
\hline \multicolumn{7}{|l|}{ Income } \\
\hline $5000-10000$ & 1.078912 & 0.2980779 & 0.27 & 0.783 & 0.63 & 1.85 \\
\hline $10000-15000$ & 1.000419 & 0.2743983 & -0.06 & 0.951 & 0.57 & 1.70 \\
\hline$>15000(\mathrm{r})$ & 1 & - & - & - & - & - \\
\hline \multicolumn{7}{|l|}{ Mother education } \\
\hline Literate $(r)$ & 1 & - & - & - & - & - \\
\hline Illiterate & 1.388086 & 0.3309909 & 1.38 & 0.169 & 0.87 & 2.21 \\
\hline \multicolumn{7}{|l|}{ Father education } \\
\hline Literate (r) & - & - & - & - & - & - \\
\hline Illiterate & 1.25752 & 0.3117022 & 0.92 & 0.355 & 0.77 & 2.04 \\
\hline \multicolumn{7}{|l|}{ Water quality } \\
\hline Improved (r) & 1 & - & - & - & - & - \\
\hline Not improved & 3.404751 & 1.179312 & 3.54 & $<0.01$ & 1.73 & 6.71 \\
\hline \multicolumn{7}{|l|}{ Toilet faculty } \\
\hline Flush/pit latrine (r) & 1 & - & - & - & - & - \\
\hline No facility & 1.482691 & 0.3928416 & 1.49 & 0.137 & 0.88 & 2.49 \\
\hline \multicolumn{7}{|l|}{ District } \\
\hline DIK (r) & 1 & - & - & - & - & - \\
\hline Charsadda & 3.58697 & 11.83281 & 4.26 & $<0.01$ & 1.70 & 6.75 \\
\hline Nowshehra & 5.44634 & 28.31439 & 5.62 & $<0.01$ & 2.48 & 9.90 \\
\hline Cons & 0.0013121 & 0.0012199 & -7.14 & $<0.01$ & 0.0002 & .018 \\
\hline
\end{tabular}


TABLE 5: Ordinal logistic regression model for undernutrition among preschool and school-going children in the affected area of Khyber Pakhtunkhwa.

\begin{tabular}{|c|c|c|c|c|c|c|c|c|}
\hline \multirow{2}{*}{ Factors } & & \multirow{2}{*}{ Estimate } & \multirow{2}{*}{ Std. error } & \multirow{2}{*}{ Wald } & \multirow{2}{*}{ Df } & \multirow{2}{*}{ Sig. } & \multicolumn{2}{|c|}{$95 \%$ confidence interval } \\
\hline & & & & & & & Lower bound & Upper bound \\
\hline \multirow{24}{*}{ Threshold } & {$[$ Malnutrition status $=0.00]$} & 1.362 & 0.761 & 3.202 & 1 & 0.074 & -0.13 & 2.85 \\
\hline & [Malnutrition status $=1.00]$ & 2.126 & 0.764 & 7.748 & 1 & 0.005 & 0.63 & 3.62 \\
\hline & Sex of the child & & & & & & & \\
\hline & Male & -0.237 & 0.181 & 1.721 & 1 & 0.190 & -0.59 & 0.12 \\
\hline & Female & 1 & . & . & 0 & . & . & . \\
\hline & Child age (months) & & & & & & & \\
\hline & $0-12$ & 2.157 & 0.901 & 5.731 & 1 & 0.017 & 0.39 & 3.92 \\
\hline & $12-24$ & 1.989 & 0.337 & 34.791 & 1 & $<0.01$ & 1.33 & 2.65 \\
\hline & $24-36$ & 1.900 & 0.287 & 43.962 & 1 & $<0.01$ & 1.34 & 2.46 \\
\hline & $>36$ & 1 & - . & - . & 0 & . & . & . \\
\hline & Maternal age & & & & & & & \\
\hline & $15-24$ & 1.282 & 0.240 & 28.525 & 1 & $<0.01$ & 0.81 & 1.75 \\
\hline & $24-34$ & 0.534 & 0.220 & 5.923 & 1 & 0.015 & 0.10 & 0.97 \\
\hline & Above 34 & 1 & . & . & 0 & . & . & . \\
\hline & Status of the HH & & & & & & & \\
\hline & IDP's & 0.174 & 0.389 & .199 & 1 & 0.655 & -0.59 & 0.94 \\
\hline & Host & 1 & . & . & 0 & . & . & . \\
\hline & Family type & & & & & & & \\
\hline & Joint family & .506 & .197 & 6.593 & 1 & 0.010 & 0.12 & 0.89 \\
\hline & Individual family & 1 & . & . & 0 & . & . & . \\
\hline & Family size & & & & & & & \\
\hline & Small & -0.107 & 0.270 & 0.158 & 1 & 0.691 & -0.64 & 0.42 \\
\hline & Medium & 0.073 & 0.228 & 0.101 & 1 & 0.750 & -0.37 & 0.52 \\
\hline & Large & 1 & . & . & 0 & . & . & . \\
\hline \multirow[t]{23}{*}{ Location } & Father occupation & & & & & & & \\
\hline & Not working & 0.324 & 0.392 & 0.682 & 1 & 0.409 & -0.45 & 1.10 \\
\hline & Part time working & -0.090 & 0.435 & 0.043 & 1 & 0.836 & -0.94 & 0.76 \\
\hline & Full time working & 1 & . & . & 0 & . & . & . \\
\hline & Mother occupation & & & & & & & \\
\hline & Not working & 0.892 & 0.575 & 2.409 & 1 & 0.121 & -0.023 & 2.02 \\
\hline & Part time working & 1.504 & 0.811 & 3.437 & 1 & 0.064 & -0.09 & 3.09 \\
\hline & Not working & 1 & . & . & 0 & . & . & . \\
\hline & Mother education & & & & & & & \\
\hline & Literate & -0.342 & 0.192 & 3.173 & 1 & 0.045 & -0.03 & -0.71 \\
\hline & Illiterate & 1 & . & . & 0 & . & . & . \\
\hline & Father education & & & & & & & \\
\hline & Literate & -0.126 & 0.197 & 0.413 & 1 & 0.521 & -0.51 & 0.26 \\
\hline & Illiterate & 1 & . & . & 0 & . & & . \\
\hline & Water quality & & & & & & & \\
\hline & Improved & -0.839 & 0.261 & 10.363 & 1 & 0.001 & -1.35 & -0.33 \\
\hline & Not improved & 1 & . & . & 0 & . & . & . \\
\hline & District & & & & & & & \\
\hline & Charsadda & -0.077 & 0.298 & 0.067 & 1 & 0.796 & -0.66 & 0.51 \\
\hline & Nowshehra & 0.038 & 0.288 & 0.018 & 1 & 0.895 & -0.53 & 0.60 \\
\hline & DIK & 1 & . & . & 0 & . & . & . \\
\hline & Toilet facility & & & & & & & \\
\hline & Flush/pit latrine & -0.939 & 0.199 & 22.308 & 1 & $<0.01$ & -1.33 & -0.55 \\
\hline
\end{tabular}


TABLE 5: Continued.

\begin{tabular}{|c|c|c|c|c|c|c|c|c|}
\hline \multirow{2}{*}{ Factors } & & \multirow{2}{*}{ Estimate } & \multirow{2}{*}{ Std. error } & \multirow{2}{*}{ Wald } & \multirow{2}{*}{ Df } & \multirow{2}{*}{ Sig. } & \multicolumn{2}{|c|}{$95 \%$ confidence interval } \\
\hline & & & & & & & Lower bound & Upper bound \\
\hline & No facility & 1 & . & . & 0 & . & . & . \\
\hline & Income & & & & & & & \\
\hline & $5000-10000$ & 0.096 & 0.23 & 0.172 & 1 & 0.67 & -0.35 & 0.54 \\
\hline & $10000-15000$ & 0.073 & 0.21 & 0.113 & 1 & 0.73 & -0.35 & 0.49 \\
\hline & $>15000$ & 1 & . & . & 0 & . & . & . \\
\hline
\end{tabular}

Charsadda, also susceptible to undernutrition based on underweight compared to children belonging to Dera Ismail Khan.

In the following Figure S5, the pyramid was constructed for children age-stratified according to gender. It showed that male children are slightly more susceptible to undernutrition based on underweight than female children.

The analysis in Table 4 revealed that children aged 1-12 months are 6.91 times $(\mathrm{AOR}=6.91,95 \% \mathrm{CI}: 1.11,13.08 ; p$ value $=0.038)$, children aged 12-24 months are 5.8 times $(\mathrm{AOR}=5.89,95 \% \mathrm{CI}: 3.84,12.01 ; p$ value $<0.001)$, and children aged 24-36 months are 4.78 times (AOR $=4.78,95 \%$ CI: $2.62,12.70$; $p$ value $<0.001)$ more at risk for underweight as compared children older age $>36$ months. Children delivered by younger mothers, aged 15-24 years, are significantly 2.89 times more likely to be underweight than children delivered by older mothers above 34 . Children who have no access to improved drinking water are 3.40 times more likely to be underweight than those who have access to improved drinking water $(\mathrm{AOR}=3.40,95 \% \mathrm{CI}$ : $1.72,6.71$; $p$ value $<0.001)$. Further analysis showed that children the belong to district Charsadda are 3.5 times more likely to be underweight $(\mathrm{AOR}=3.58,95 \% \mathrm{CI}: 1.70,6.74 ; p$ value < 0.001 ), and children from district Nowshera are 5.44 times more likely to be underweight $(\mathrm{AOR}=5.44,95 \% \mathrm{CI}: 2.4$, 9.91, $p$ value $<0.001)$ as compared to children belongs to Dera Ismail Khan.

We have also applied the ordinal logistic regression model when the response variable is categorized into three levels: normal children, moderately prevalence of malnutrition, and severe prevalence of malnutrition (Table 5). The analysis showed almost similar significant socioeconomic determinants as in the binary logistic model, and it is found that child age, maternal age, family type, mother education, water quality, and toilet facility significant $(p$ value $<0.05)$ risk factors of undernutrition.

\section{Discussion}

The prevalence of underweight was high in preschool and school-going children in the flood-hit areas of Khyber Pakhtunkhwa, Pakistan. It accounts for $25.2 \%$ of children aged 560 months, while $23.3 \%$ were underweight in children aged $>5-12$ years. The prevalence of underweight was higher in young age mothers $(40.6 \%)$, younger age children $(71.4 \%)$, large family size $(28.4 \%)$, joint family $(27 \%)$, and no toilet facility $(28.9 \%)$. The findings also showed that the prevalence of underweight was less in children with literate par- ents than children with illiterate children. The significant risk factor that caused underweight was children of lower age, young mothers, children's access to unimproved water sources, and location (districts) due to environmental and constant flood consequences. We are the first study to report the determinants of underweight in the flood-hit areas of Pakistan. It is necessary to timely document the incidence of nutritional status reduce malnutrition. Timely documentation for improved communication is important [20].

In both age groups, female children were more likely to be underweight than boys in the flood-hit areas of KP. We collected data in Khyber Pakhtunkhwa, where the documented under five underweight according to the NNS 2018 was $23.1 \%$, more than our presented data [19-21]. It means that flood has a negative impact on the prevalence of underweight-based malnutrition. We are the first to report underweight in more than five years' children in the floodhit areas of Pakistan. Young women, infants, children, and adolescents are usually at high risk of malnutrition. Proper nutrition at an early age, including nutrition 1000 golden days, have long-term benefits to reduce this burden in later stages of life [14]. The high prevalence in $>5-12$ years children might be because the children are still growing but not getting enough calories and nutrients from a balanced diet during a disaster situation [22], which makes them underweight.

Due to environmental and constant floods, the locations are high and usually have a high prevalence of undernutrition. The impact of the flood on nutritional status is negative, which leads to poor nutritional status in under 5 and $>5-12$ year children $[23,24]$. Therefore, the aftermath of floods should be seriously considered to eradicate malnutrition in children and their mothers [25].

Clean water is very important for every age group, including children. Safe drinking water and good sanitation and hygiene reduce the burden of undernutrition. Contaminated water and poor sanitation and hygiene status deteriorate child nutritional status causing undernutrition [26]. Unimproved water intake in flood-hit areas leads to stunting and MUAC-based undernutrition [23, 24]. Improved water and sanitation and toilet facilities lower mortality, diarrhea, and stunting in under-fie children [27].

Floods like disasters have the potential to cause food shortages and many nutritional issues in affected and sounding areas. Although modern transportation and information exchange means have changed the food distribution and consumption system, some communities have to rely on their crops, fruits, products, and indigenous nutritional 
items. At the same time, the vulnerable population living in hard areas and distanced populations could have the severe effect of flooding in terms of their nutritional needs. It impacts in two ways; the local crops eliminate, destroy much of saved items and affect production. Second, increased price of the food items and decreased the purchasing power of the people from flood-affected areas due to periodic unemployment and the burden of diseases.

The emergency response and mitigation structure in Pakistan are at a developing stage. To respond against the underweight issue of children due to flooding requires a comprehensive multisector emergency response and social development program involving all concerned organizations and separate relief funds. After the flooding events of 2001 and 2010 government of Pakistan implemented immediate emergency rescue activities, which saved lives and provided food essential for healthy life [28]. Envisioning underweight due to malnutrition in 2011, the government requested UNICEF, WFP, and other partners to provide nutritional supplements for children and pregnant women in affected areas [29].

The Government of Pakistan and international partners conducted "The Flood Affected Nutrition Survey (FANS)" to assess child nutrition status under five years of age in floodaffected communities [30]. The assessment provided the baseline information about malnutrition and loss of nutritional elements for the children and its potential consequences. The response to underweight children due to flooding is linked with federal and provincial government policies. Both governments are concerned with providing concrete steps with the support of national and international organizations to treat and manage underweight and malnutrition situations [31].

Interventions made to regulate the supplies of food items to the markets were not subsidized that each household could acquire daily. The government of Pakistan engaged many national and international NGOs in flood-affected areas and built coordination with the help of UNICEF and NDMA. Along with social and economic services, the organizations facilitated the affected families in providing ration, nutrition supplements, and cooked and uncooked food items for extended periods [32]. The main aim of the interventions was to eradicate the issue of malnutrition, including underweight among the affected children. Another program in collaboration with Action Against Hunger (ACF) was also launched with the name of Pakistan Emergency Food Security Alliance (PEFSA) program in 2011 in areas of Sindh province [33]. The output achieved by the program included timely identification and treatment of acute malnutrition and improved public awareness regarding underweight and the importance of nutrition during a flood situation.

The government of Pakistan, along with international partners, developed National Nutrition Cluster Preparedness and Response Plan to mainstream the activities and actions of partners for improving the nutritional statuses of vulnerable communities. The plan envisaged to emergencies exacerbate the underlying nutrition crisis in Pakistan [34]. 2010, 2011, and 2012 monsoon response the malnutrition for populations already suffering from emergencies of floods and monsoon flashings and had aftershocks. Despite many efforts, the targeted, planned step seems less likely to be taken to provide adequate relief for the children underweight in flood-hit areas. Studies reveal that Specialized Nutritious Foods (SNF) should be initiated to reduce malnutrition, including underweight situations. The government could start comprehensive targeted SNF provision interventions to all victim households in the affected area to support malnutrition issues. During last year, the Ministry of Poverty Alleviation and Social Protection planned the initiatives, including SNF implementation, to improve the nutritional status of children under two years and pregnant women [35]. Public emergency services such as ambulances would help mitigate services to prone areas, which may help reduce the disease burden [36].

There were certain limitations accounted for in this study. First, the study was a cross-sectional study that shows a causal impact. Second, this study was conducted after 4-5 years after the flood and reported this year. The reason is that we wanted to check the aftermath and long-term consequences of the flood. Flood is still a health concern affecting the nutritional status of children. Also, the role of government needed to be highlighted for preparedness in emergencies. Nevertheless, the current study is the first study highlighting the role of government and investigating the risk factors of underweight in the flood-affected areas of Pakistan.

\section{Conclusion}

In conclusion, risk factors of underweight, including child age, maternal age, family type, mother education, water quality, and toilet facility, should be appropriately targeted in the flood-hit areas of Pakistan. Floods often create longterm consequences for developing societies and marginalized people living in hard areas. Such disasters mostly bring social, economic, and health-related consequences for victims and government administrations. Such consequences of floods have been observed in the flood-affected areas of Pakistan. In Pakistan, it is uncommon to allocate the annual proportion of budgeting for food and nutrition security of the vulnerable population in case of flooding. During a disaster, the government has to engage the partners and funding agencies for preparedness and response to food and nutrition issues. Governments should preallocate budgetary resources and enhance the emergency preparedness levels to facilitate the communities with flooding incidents. SNF initiatives should also be included in the preparedness plans to facilitate the communities suffering from underweight child crises due to flooding and other similar hazards. Emergency services such as functional Rescue 1122 services may be helpful in pre and postdisaster time to reduce the disease burden.

\section{Data Availability}

All data are included in this manuscript. 


\section{Ethical Approval}

This study was conducted according to the guidelines laid down in the Declaration of Helsinki, and the ethical committee of The University of Agriculture, Peshawar, Pakistan, approved all procedures involving research study participants (Approval number $=002$ ).

\section{Consent}

Written informed consent was obtained from all subjects.

\section{Conflicts of Interest}

All authors reported no conflict of interest.

\section{Authors' Contributions}

Ijaz ul Haq and Zafar Mehmood conceptualized, designed, and wrote the original draft. Bilal Ahmed, Ihtisham Ul Haq, and Jahan Shah collected the data. Amjad Khan, Shahbaz Ahmad Zakki, Muhammad Shahzad, and Javed Muhammad contributed to editing and formal analysis. Yufang Xue and Jielian Xu contributed in data curation. Xiaoshuang Chen and Jing Miao reviewed the article. Ijaz ul Haq and Xiang He equally contributed as first authors.

\section{Acknowledgments}

The authors pay special thanks to the Director Nutrition Nuclear Institute for Food and Agriculture (NIFA) Peshawar, Pakistan, and the whole laboratory staff for their technical support. This research project (2227) was financially supported by the Higher Education Commission (HEC) of Pakistan.

\section{Supplementary Materials}

Figure S1 (a) shows the parentage of underweight and normal children in each age group and tells that there is a decreasing trend of malnutrition with the age of children because there is a high prevalence of stunting at low age groups as compared to higher age group ( $>36$ months). Figure S1 (b) expresses the percentage of underweight and normal children for each age group calculated within the overall percentage of underweight and normal children in the target population. Figure S2 shows that out of total sample of size 656; $57.74 \%$ boys are with normal weights whereas $42.26 \%$ of girls are with normal weights. It is evident from the figure that male children are slightly more susceptible to underweight-based malnutrition than female children in the flood-affected areas of Khyber Pakhtunkhwa (KP). Figure S3 shows that out of total observed underweight children in the study area district, Nowshera is contributing the highest prevalence of underweight based malnutrition (68.42\%) followed by district Charsadda (46.63\%) and Dera Ismail Khan is the lowest (1.974\% only). Figure S4 shows the pyramid for children age-stratified according to the districts. It has been shown that children belonging to district Nowshera were at high risk of underweight based undernutrition followed by district
Charsadda also susceptible to undernutrition based on underweight compared to child belongs to Dera Ismail Khan. In the following Figure S5, the pyramid was constructed for children age-stratified according to gender. It showed that male children are slightly more susceptible to undernutrition based on underweight than female children. (Supplementary Materials)

\section{References}

[1] J. M. Rodriguez-Llanes, S. Ranjan-Dash, A. Mukhopadhyay, and D. Guha-Sapir, "Looking upstream: enhancers of child nutritional status in post-flood rural settings," PeerJ, vol. 4, article e1741, 2016.

[2] M. Singh, M. S. Alam, P. Majumdar, B. Tiwary, H. Narzari, and Y. Mahendradhata, "Understanding the spatial predictors of malnutrition among 0-2 years children in India using path analysis," Front Public Health, vol. 9, article 667502, 2021.

[3] D. D. Saulnier, K. Brolin Ribacke, and J. von Schreeb, "No calm after the storm: a systematic review of human health following flood and storm disasters," Prehospital and Disaster Medicine, vol. 32, no. 5, pp. 568-579, 2017.

[4] J. M. Rodriguez-Llanes, S. Ranjan-Dash, O. Degomme, A. Mukhopadhyay, and D. Guha-Sapir, "Child malnutrition and recurrent flooding in rural eastern India: a communitybased survey," BMJ Open, vol. 1, no. 2, article e000109, 2011.

[5] C. Kousky, "Impacts of natural disasters on children," The Future of children, vol. 26, pp. 73-92, 2016.

[6] E. J. Kistin, J. Fogarty, R. S. Pokrasso, M. McCally, and P. G. McCornick, "Climate change, water resources and child health," Archives of disease in childhood, vol. 95, no. 7, pp. 545-549, 2010.

[7] P. Joshi, S. Kaushal, B. S. Aribam et al., "Recurrent floods and prevalence of diarrhea among under five children: observations from Bahraich district Uttar Pradesh, India," Global Health Action, vol. 4, p. 6355, 2011.

[8] UNICEF, "UNICEF humanitarian action update; South Asia Floods," 2007.

[9] C. JJALPLAO, Responding to flood disasters: learning from previous relief and recovery operations, 2014.

[10] B. Koch, Flood Preparedness and Response: Strategies for Families, North Dakota State University, 2019.

[11] J. Meyer, Emergency Food Aid Assistance to Flood-Affected People in South-Western Bangladesh: Household Livelihood Assessment Report, DFID, London, 2001.

[12] Care. 46 Million People Severely Affected by South Asia Floods, 2007, October 2007, https://www.care.org/news-and-stories/ press-releases/46-million-people-severely-affected-by-southasia-floods/.

[13] H. Warraich, A. K. Zaidi, and K. Patel, "Floods in Pakistan: a public health crisis," Bulletin of the World Health Organization, vol. 89, pp. 236-237, 2011.

[14] WHO, Malnutrition, 2021, June 2021, https://www.who.int/ news-room/fact-sheets/detail/malnutrition.

[15] UNICEF, The State of the World's Children 2013: Children with Disabilities, UNICEF, New York, 2013.

[16] S. Dang, H. Yan, and D. Wang, "Implication of World Health Organization growth standards on estimation of malnutrition in young Chinese children: two examples from rural western China and the Tibet region," Journal of child health care, vol. 18, pp. 358-368, 2014. 
[17] I. ul Haq, M. Asra, Q. Tian et al., “Association of infant and child feeding index with undernutrition in children aged 659 months: a cross-sectional study in the Maldives," The American Journal of Tropical Medicine and Hygiene, vol. 103, no. 1, p. 515, 2020.

[18] WHO, Growth reference 5-19 years, 2007.

[19] M. D. Onis, A. W. Onyango, E. Borghi, A. Siyam, C. Nishida, and J. Siekmann, "Development of a WHO growth reference for school-aged children and adolescents," Bulletin of the World health Organization, vol. 85, pp. 660-667, 2007.

[20] M. A. Khan, N. Nilima, J. Prathibha, B. Tiwary, and M. Singh, "Documentation compliance of in-patient files: a cross sectional study from an east India state," Clinical Epidemiology and Global Health, vol. 8, pp. 994-997, 2020.

[21] Aga Khan University, Ministry of National Health Services, regulations \& coordination (Pakistan), Pakistan Medical Research Council, UK aid direct, United Nations Children's Fund (UNICEF), Pakistan National Nutrition Survey, 2018.

[22] NHS, Underweight children aged 6 to 12April 2020, https:// www.nhs.uk/live-well/healthy-weight/underweight-children6-12-advice-for-parents/.

[23] I. U. Haq, Z. Mehmood, N. Khan et al., "Risk factors of midupper arm circumference (MUAC) based child malnutrition in the flood-affected areas of Pakistan: a cross-sectional study: child malnutrition in flood-hit areas," Ecology of Food and Nutrition, vol. 60, pp. 1-17, 2021.

[24] Z. Mehmood, T. Afzal, N. Khan et al., "Prevalence and determinants of stunting among preschool and school-going children in the flood-affected areas of Pakistan," Brazilian Journal of Biology, vol. 82, p. 82, 2021.

[25] J. M. Rodriguez-Llanes, S. Ranjan-Dash, A. Mukhopadhyay, and D. Guha-Sapir, "Flood-exposure is associated with higher prevalence of child undernutrition in rural eastern India," International Journal of Environmental Research and Public Health, vol. 13, p. 210, 2016.

[26] Organization WH, Improving Nutrition Outcomes with Better Water, Sanitation and Hygiene: Practical Solutions for Policies and Programmes, 2015.

[27] G. Fink, I. Günther, and K. Hill, "The effect of water and sanitation on child health: evidence from the demographic and health surveys 1986-2007," no. 40, pp. 1196-1204, 2011.

[28] Nations U, Pakistan flood emergency response plan, UNOCHA, 2010.

[29] M. Scott, Heavy rains and dry lands don't mix: Reflections on the 2010 Pakistan Flood, NASA earth is observatory, 2011.

[30] Department of Health Khyber Pakhtunkhwa (KP), Flood Affected Nutrition survey of Khyber Pakhtunkhwa (KP) Province Pakistan, Report, 2010, https://www.humanitarianresponse.info/ sites/www.humanitarianresponse.info/files/documents/files/ FANS_KPK__2010_Final\%20\%28March\%2023\%2C\% 202011\%29.pdf.

[31] UNICEF, Pakistan floods uncover dire nutrition situation. Six months after the floods, reliefweb, 2011, https://www .actioncontrelafaim.org/en/publication/pakistan-nutritionmainstreaming-in-flood-response-programming/.

[32] G. Sadiq and Pakistan National Committee of IUCN, Flood Relief Activities, IUCN, 2012.

[33] A. I. Pakistan, Nutrition mainstreaming in flood response programming. March 2011. PEFSA food security, livelihoods and nutrition analysis for the flood response, 2011.
[34] OCHA, Pakistan national nutrition cluster preparedness and response plan. Humanitarian Response, United Nations Office for the Coordination of Humanitarian Affairs (OCHA), 2013.

[35] W. Pakistan, WFP Pakistan Country Brief, reliefweb, 2020.

[36] B. Tiwary, N. Nilima, P. Majumdar, M. Singh, and M. A. Khan, "Quality of services provided by public funded ambulance program: experience from a northern state in India," Clinical epidemiology and global health, vol. 8, pp. 962-966, 2020. 